\title{
STUDIES AND APPLICATION OF REMOTE SENSING RETRIEVAL METHOD OF SOIL MOISTURE CONTENT IN LAND PARCEL UNITS IN IRRIGATION AREA
}

\author{
H. Zhu' ${ }^{1}$, H.L. Zhao ${ }^{2}$ *, Y.Z. Jiang ${ }^{2}$, W.B. Zang ${ }^{1}$ \\ ${ }^{1}$ Research Center on Water and Drought Disaster Reduction Technical Engineering, China Institute of Water Resources and \\ Hydropower Research -zhuhe@iwhr.com \\ ${ }^{2}$ Department of Water Resources Research, China Institute of Water Resources and Hydropower Research.
}

KEY WORDS: Land Parcel Unit, Soil Moisture Content, Remote Sensing Retrieval, Water Resource Management, Irrigation Area

\begin{abstract}
:
Soil moisture is one of the important hydrological elements. Obtaining soil moisture accurately and effectively is of great significance for water resource management in irrigation area. During the process of soil moisture content retrieval with multiremote sensing data, multi- remote sensing data always brings multi-spatial scale problems which results in inconformity of soil moisture content retrieved by remote sensing in different spatial scale. In addition, agricultural water use management has suitable spatial scale of soil moisture information so as to satisfy the demands of dynamic management of water use and water demand in certain unit. We have proposed to use land parcel unit as the minimum unit to do soil moisture content research in agricultural water using area, according to soil characteristics, vegetation coverage characteristics in underlying layer, and hydrological characteristic into the basis of study unit division. We have proposed division method of land parcel units. Based on multi thermal infrared and near infrared remote sensing data, we calculate the ndvi and tvdi index and make a statistical model between the tvdi index and soil moisture of ground monitoring station. Then we move forward to study soil moisture remote sensing retrieval method on land parcel unit scale. And the method has been applied in Hetao irrigation area. Results show that compared with pixel scale the soil moisture content in land parcel unit scale has displayed stronger correlation with true value. Hence, remote sensing retrieval method of soil moisture content in land parcel unit scale has shown good applicability in Hetao irrigation area. We converted the research unit into the scale of land parcel unit. Using the land parcel units with unified crops and soil attributes as the research units more complies with the characteristics of agricultural water areas, avoids the problems such as decomposition of mixed pixels and excessive dependence on high-resolution data caused by the research units of pixels, and doesn't involve compromises in the spatial scale and simulating precision like the grid simulation. When the application needs are met, the production efficiency of products can also be improved at a certain degree.
\end{abstract}

\section{INTRODUCTION}

Remote sensing which owns the ability to observe the underlying surface in an extensive, timely and fast way is an important means to acquire the data about regional soil moisture. Multisource remote sensing combination observation has important significance for continuous and stable monitoring of key hydrologic features in the irrigation area and contributes to fine agricultural water management. However, remote sensing sources which can be used for soil moisture inversion mainly include microwave remote sensing data and visible light-thermal infrared remote sensing data. There are many varieties available for choice. Spatial resolution differences are obvious, and fine water resource management has appropriate spatial scale demand for soil moisture data, which results in the problem of transforming multisource remote sensing observation data to suitable spatial scale meeting agricultural water management demand. In the irrigation area, mature automatic ground observation station network has been generally built for soil moisture. Synergistic observation of multisource remote sensing and ground can boost reliability of soil moisture data. However, the matching problem of ground monitoring point scale data and remote sensing monitoring surface scale data exists. Thus, to gain continuous and stable observation data of regional soil moisture, spatial scale transformation of multisource observation data oriented to suitable spatial scale is also a problem to be solved urgently.

In general, point or pixel is often used as the computing element in point-surface or surface-surface scale matching for soil moisture. The very high requirement is proposed for positioning accuracy of pixel and point, and representativeness of point data. From the perspective of water resource business, field land (basic unit of field land management with the representative attribute of soil moisture) is used as the research unit. Meanwhile, technical feasibility and cost are taken into account. In this way, precision demand is met, and there is application value. Besides, technical difficulty and low precision can be avoided when pixel scale is used as the unit.

In order to meet fine agricultural water management demand, the setting of appropriate spatial scale should aim to satisfy dynamic water demand of water application unit in a period. Usually, agricultural water unit should have the same vegetation and soil attribute so as to make sure water demand of crops and water resource quantity contained in soil in the same period are consistent. Meanwhile, the unit needs same catchment feature and water supply source to ensure acquisition of consistent irrigation amount in the same irrigation period. Thus, vegetation cover features and hydrological features of soil and underlying surface are incorporated in water unit division basis to divide the uniform

\footnotetext{
* Corresponding author. E-mail address : zhhbslsd@aliyun.com..
} 
field land of soil, vegetation and hydrological features as the minimum research unit of soil moisture in the agricultural water.

This research attempts to take the land with the uniform crop and soil attribute as the research unit to explore land division principle and method and analyze spatial scale transformation method. Soil moisture gained from remote sensing inversion and ground observation is transformed to land scale, and Hetao Irrigation Area is chosen as the research area foe method application. Then, the results are analyzed, and the rationality of results is verified.

\section{STUDY AREA AND DATA}

\subsection{Study Area}

The research area is Hetao Irrigation Area in Inner Mongolia. Hetao Irrigation Area is located at the riverside of Yellow River in Inner Mongolia and covers an area of about $1784 \mathrm{mu}$. The distance between the east and the west is long and narrow, about 3 times of south-north distance. The irrigation area is mainly plain area, with fertile soil texture, and it is easy to cultivate. It is an important grain production base of the state. With the sufficient heat in the irrigation area, the crops can be ripe annually. The crops mainly include spring wheat, corns and sunflowers as well as tomatoes, beets, melons, fruits and vegetables in summer and autumn. About soil type, Hetao Plain research area is in arid and semi-arid climate area. Under the influence of bioclimate condition and irrigation by diverting water from the Yellow River on soil-forming process, the research area is based on cumulated irrigated soil with low organic content, nitrogen deficiency, little phosphorus and surplus potassium. The test result shows that organic content in soil is related to soil type. The soil with high value is clay, and the soil with low value is sandy soil.

\subsection{Data}

The research point-in-time was April 20, 2015. The main data include measured data of ground single point, and remote sensing inversion data.

\subsubsection{Soil moisture data on point scale from ground monitoring station}

Soil characteristics and crop planting structure in the irrigation area as well as the representative capacity of monitoring points for soil moisture characteristics in the irrigation area were overall considered in this research. Based on the principle of space uniformity and moderate workload, 39 manual monitoring points for soil moisture were evenly distributed in Hetao Irrigation Area. Single point measured data about soil moisture were measured by manual sampling on the ground. The sampling time was decided by referring to satellite transit time. 3 layers were sampled every time: $10 \mathrm{~cm}, 20 \mathrm{~cm}$ and $30 \mathrm{~cm}$ soil layers. Weighing method was used to measure soil moisture, i.e. weight moisture content. In this research, sampling time was April 20, 2015, and the research soil layer was $10 \mathrm{~cm}$ soil layer.

\subsubsection{Regional soil moisture data derived from remote} sensing retrieval

HJ satellite data were applied in this research. Soil moisture inverted by tvdi index method was used as the observation data of remote sensing area. The observation time and ground single point monitoring time were consistent, i.e. April 20, 2015.

\section{RESEARCH METHOD}

\subsection{General Thought}

Land refers to the basic unit of field water management in which representativeness attribute of soil moisture is added. Land is used as the research unit of soil moisture, which can meet business demand in terms of precision, have application value and avoid technical difficulty and low precision brought by use of pixel scale as the research unit.

Scale transformation methods of remote sensing data statistics mainly include scale transformation methods based on pixel unit, object unit, physical mechanism and geographic space information. The principles of these methods are different, and the application effects are also different under different conditions. In view of ensuring business application feasibility and taking full advantage of geographic space information of remote sensing data, the method based on geostatistical analysis is applied in this research to conduct statistics of multisource soil moisture data on field land scale to complete spatial scale transformation (Wang et al., 2012). The detailed work flow is as follows:

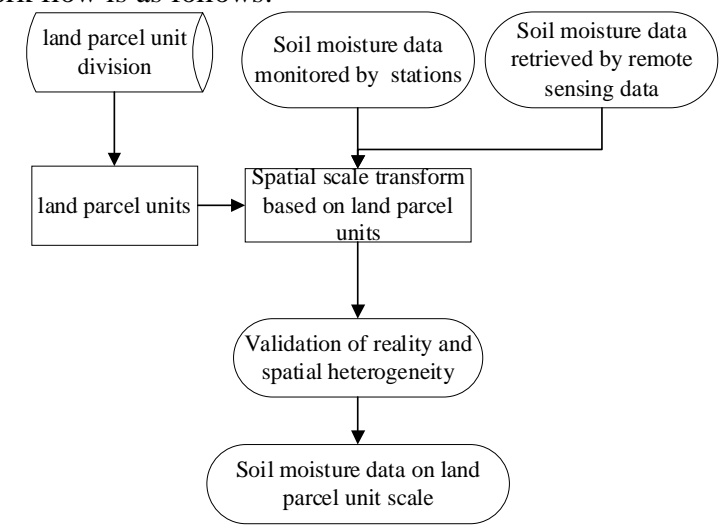

Figure 1. Spatial scale transformation flow of multisource soil moisture

Firstly, land parcel unit division is conducted in this research. On this basis, land scale transformation of soil moisture data gained through ground point monitoring and multisource remote sensing is carried out. To guarantee rationality of land scale transformation, authenticity and spatial heterogeneity test should be conducted. The ground measured data and the data matched with spatial scale of multisource soil moisture are gained. Remote sensing inversion of soil moisture is achieved through tvdi index method and establishment of statistical relation with ground monitoring of soil moisture.

\subsection{Land Parcel Unit Division}

Land parcel unit division is the research emphasis in this part. To make the divided land have large space consistency of soil moisture, physicochemical characteristics of soil, vegetation cover characteristics of underlying surface, and hydrologic characteristics should be included in the land division basis. The land with the uniform soil, vegetation and hydrologic characteristics is divided as the minimum research unit of soil 
moisture research in the agricultural water area. In the division process, the division method of hydrological response unit with the same property may be referred to in the research on hydrologic model of basin. Hydrological response unit is the minimum research unit of hydrologic model of basin, and is also the area summation of land surface with same vegetation cover, soil type and management conditions in the basin. It is assumed to be the uniform hydrological response behavior in the basin(Chi, 2013). Usually, in the division of hydrological response unit, it is necessary to confirm the ridge line of the basin as basin boundary according to DEM of the basin, find out the steepest slope, set the minimum catchment unit and generate the river network of the basin; then, watershed serves as the sub-basin boundary to generate sub-basin; the sub-basin boundary is superposed according to vegetation form and soil type data of sub-basin; after statistics of area critical value of vegetation and soil type, screening and segmentation are carried out to generate hydrological response units(Zheng, 2011).

Compared with natural basin, although agricultural water area (mainly refer to irrigation area) shows certain confluence characteristic, the river systems in the irrigation area are mostly artificial ditches rather than the river systems which form due to confluence of natural valley terrain. With regard to the division of land parcel unit in the irrigation area, especially for plain irrigation area, the division method has many differences with the natural basin. The differences between irrigation area and natural basin are as follows: the terrain in the irrigation area is mostly flat and distributed in the plain area. The manual transformation of irrigation area changes the elevation of ditches. Thus, it is very difficult to automatically extract river network by directly utilizing the difference of terrain elevation, and it is necessary to manually correct the elevation. Due to the complexity of river network, runoff and confluence mode in the irrigation area in which artificial ditch deepens, it is difficult to automatically or artificially judge runoff and confluence direction. In the irrigation area, the field ridge serves as the catchment unit, which is different from the natural basin where hydrological response unit is used to gather water source. Even after artificial correction, the elevation is hard to gain the rational water unit, and will disconnect with water management in the irrigation area. Therefore, the new concept of land as the research unit is proposed in the research on unit division in the irrigation area.

In this research, Hetao Irrigation Area based on canal irrigation is taken for example to divide the land. The detailed division thought is as follows:

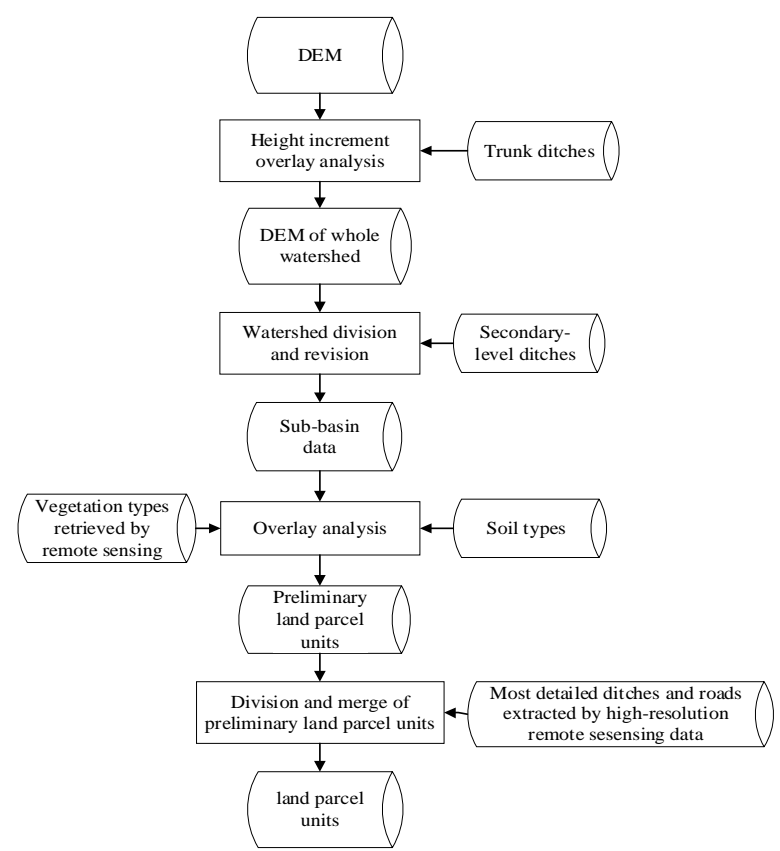

Figure 2. Technical route of land parcel unit division in the irrigation area

First of all, artificial ditches in the irrigation area are used as the watershed to divide the basin, and ditches are divided according to the scale. The flow and scale of high-level ditches are large, and they are generally trunk ditches. Secondary ditches are usually branch trunk ditches. Then, data preparation and data pre-processing are conducted according to actual conditions of irrigation area. The data to be prepared include DEM, soil type, multi-level ditch vector extracted from high-resolution satellite and vegetation form, etc. Then, operation starts according to the technical route, including utilizing first-level ditch data for elevation increment superposition of DEM; utilizing second-level ditch data for basin segmentation of DEM after data processing to gain subbasin data; overlay analysis on sub-basin data, vegetation form and soil type to gain preliminary land parcel unit; utilizing the fine ditch and road extracted to divide and merge preliminary land parcel unit so as to gain land parcel unit; finally, utilizing land parcel unit for regional statistics of multisource soil moisture data to gain soil moisture data with uniform land scale.

\subsection{Land Scale Transformation}

At present, data scale transformation method of earth surface parameters gained from remote sensing inversion is generally based on fixed pixel, grid or point data, and there is no scale transformation research aiming at irregular land parcel unit. Usually, during scale transformation of regular unit, transformation methods based on statistics or physical mechanism take pixel or grid as the basic distance unit to consider spatial relationship among several units. In this research, in view of land irregularity, the land center needs to be set as the assignment point location of land attribute value, and the distance between land center and pixel center is used as the basic distance unit to study the spatial relationship. In addition, since the land shape is not regular and the inclusion 
relation with pixel is not uniform, adaptive judgment of the inclusion relation between land parcel unit and pixel is required to confirm the scale deduction direction. Scale transformation used in this research is geostatistical transformation method based on the correlativity between land center and pixel center. The detailed work flow is as follows:

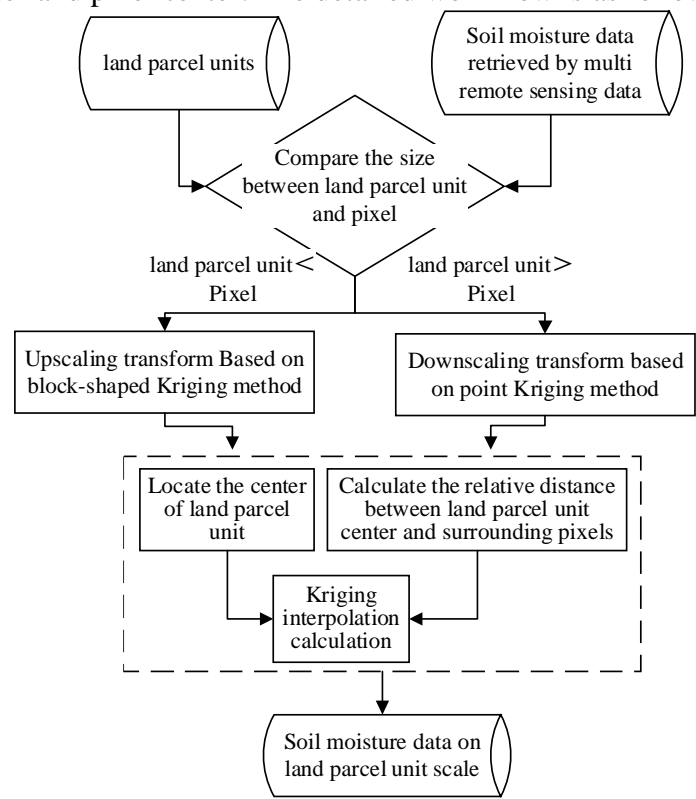

Figure 3. Land-based scale transformation process of soil moisture

Scale transformation direction (i.e. upscaling or fall downscaling) is judged according to the size relationship between land parcel unit and remote sensing inversion of soil moisture. When land parcel unit boundary is included in the pixel, downscaling transformation will be conducted; on the contrary, upscaling transformation will be conducted. Then, the relative distance between land parcel unit center and surrounding pixel is confirmed for land Kriging upscaling calculation or point Kriging downscaling calculation. Finally, soil moisture of land parcel unit is outputted.

Currently, common scale transformation methods include interpolation method and convolution method. These methods only aim at pixel and do not take into account of space structure of data, so they are not suitable for upscaling transformation and have obvious application shortcomings. Other scale transformation methods utilizing pure mathematical statistics need to introduce external parameters or data with fine scale, so their application is restricted. Thus, in view of accuracy and practicability of scale transformation methods, Kriging interpolation method is used for scale transformation in this research. The method takes into account of spatial position relationship between points, and does not need to introduce auxiliary data, which ensures method accuracy and applicability to certain degree. To be specific, point Kriging method and block-shaped are used for upscaling and downscaling calculation respectively, with the help of GIS platform.

\subsubsection{Downscaling transformation based on point Kriging method}

During downscaling interpolation calculation, it is supposed that each pixel value of raw image is a point value. 9 pixels may be taken as a calculation window. As shown in the following figure, downscaling interpolation calculation is conducted for No.5 pixel, and it can be decomposed into 4 points (i.e. 4 small pixels around No.5 pixels). No. 1 point of small pixels can be gained through Kriging downscaling transformation of the data of 5 points of the large pixel(Liu, 2007).

In this way, weighting coefficient of No. 1 point of small can be gained through estimation of 4 original pixel points.

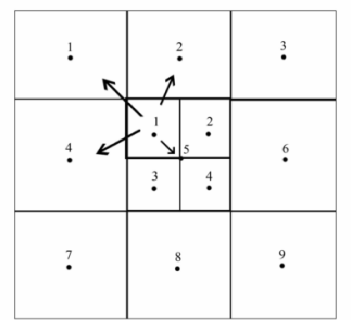

Figure 4. Sketch map for downscaling transformation

\subsubsection{Block-shaped Kriging upscaling transformation}

This research takes into account of land and remote sensing inversion of soil moisture. When land parcel unit is larger than the pixel, upscaling transformation of remote sensing inversion data is required to match with soil moisture data, i.e. measured point - pixel upscaling transformation. Pixel upscaling transforma -tion is also needed during transformation from high-resolution soil moisture data to low-resolution data. Here, block-shaped Kriging upscaling transformation is applied to estimate the mean value of central block. Since data structure is not changed, the principle of block-shaped Kriging method is same with that of point Kriging method.

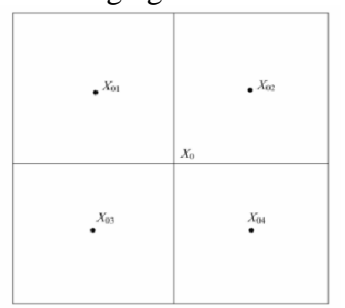

Figure 5. Sketch map for upscaling transformation

During upscaling transformation, each block corresponds to the resolution ratio under the required scale. Measured point data or pixel point data of image serve as the sampling point data, and the mean value of each land parcel unit is estimated by block-shaped Kriging.

\subsubsection{Analysis of spatial heterogeneity}

To guarantee rationality of data space structure after transformation, spatial heterogeneity analysis for data is usually required before and after transformation, except meeting the required scale.

Spatial heterogeneity refers to inconsistent degree or variation degree of space parameter attribute in space. It reflects space complexity of space parameter attribute, including space structure and space correlation degree. Scholars proposed to characterize spatial variability of space parameters with 
covariance or variation function many years ago and provided effective tools for analysis of spatial variability. is supposed to be regional random variable which meets second-order stationary hypothesis and intrinsic hypothesis. Theoretical variation function model is often unknown, and it needs to be set according to experience and sampling. For various space separation distance values, theoretical model is needed to simulate a series of spatial heterogeneity values (Dong, 2014). Here, exponential model may be used for estimation. The data after scale transformation are analyzed with variation function. If the change trend of variation function and core parameters do not change a lot, this can meet requirements.

\section{RESULT AND DISCUSSION}

\subsection{Land Parcel Unit Division}

Based on the above land division method, crop variety, soil type, ditch system and road conditions of Hetao Irrigation Area are extracted by combining the land division experience of Yichang Irrigation Area, and the land division result of the irrigation area is shown in the following figure.

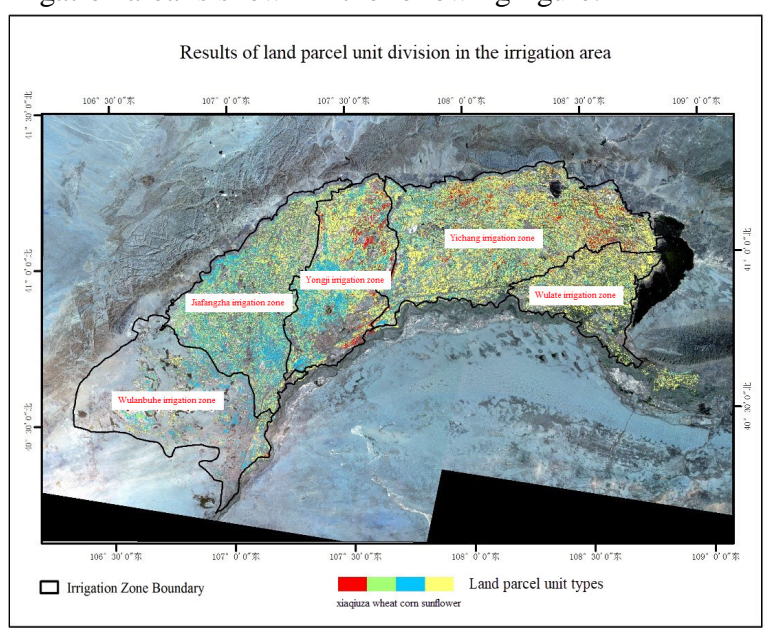

Figure 6. Land parcel unit division results in Hetao

Note: Hetao irrigation area is divided by five irrigation zones including Jiefangzha, Wulate, Wulanbuhe, Yichang, Yongji irrigation zones.

Because land division mainly refers to crop plantation, the land parcel unit is distinguished by main crop varieties. It is known from the data collection and field survey that, four kinds of crops are mainly planted in Hetao Area, i.e. coarse cereals in summer and autumn, wheat, corn and sunflower. Coarse cereals in summer and autumn include melons and tomato, etc. Corn and wheat land parcel units are mainly distributed in western Wulanbuhe, Jiefangzha and Yongji irrigation zone, while the land parcel units in eastern Yichang and Wulate irrigation zone are dominated by coarse cereals in summer and autumn, and sunflower.

\subsection{Scale Transformation Validation}

In accordance with the above transformation method, soil moisture gained from remote sensing inversion is transformed to land scale, and the data effectiveness after transformation is verified. In this research, the dates when ground measured data are collected well are chosen to verify land scale transformation. The example data are HJ-1B thermal infrared and multispectral data gathered on April 20, 2015. tvdi index is calculated with thermal infrared and multispectral data, and the statistical relationship is established with soil moisture monitored on the ground. Then, the soil moisture of the whole research area is calculated.

Firstly, scale transformation direction (i.e. upscaling or fall downscaling) is judged according to the size relationship between land parcel unit and remote sensing inversion of soil moisture. It is required to contrast the size relationship between all land parcel units and pixel to screen the land parcel units greater than the pixel for pixel upscaling; on the contrary, downscaling is conducted. Then, barycenter positions of land parcel units and pixel are extracted for autocorrelation analysis. As introduced above, semivariance means of 4 variation directions are selected to construct semivariance function model. Step size is defined as the minimum Euclidean distance between barycenters, and semivariance fitting equations of multiple sampling points are compared.

\begin{tabular}{|c|c|c|c|c|c|}
\hline $\begin{array}{c}\text { Scaling } \\
\text { direction }\end{array}$ & $\begin{array}{c}\text { meanEr } \\
\text { ror }\end{array}$ & $\begin{array}{rlc}\text { rootMea } \\
\text { nSquare }\end{array}$ & $\begin{array}{c}\text { meanSta } \\
\text { ndardize } \\
\mathrm{d}\end{array}$ & $\begin{array}{c}\text { rootMea } \\
\text { nSquare } \\
\text { Standard }\end{array}$ & $\begin{array}{c}\text { meanErr } \\
\text { orStanda } \\
\text { rdized }\end{array}$ \\
\hline Upscaling & 0.0110 & 0.4809 & 0.0115 & 0.9114 & 0.4722 \\
Downscaling & 0.0105 & 0.4797 & 0.0108 & 0.9107 & 0.4722 \\
\hline
\end{tabular}

Table 1. Parameter statistical table of land parcel units and pixels cross validation

Cross validation shows forecast error mean deduced with two scales is close to 0 , indicating the precision of prediction is good. Mean square root approaches mean standard error, close to 0 . This means discreteness is small and correlation is good. Standard mean square root is within the rational scope (0.908$1.084)$, indicating variability estimation of predicted value is good.

In the end, result reliability verification after transformation is conducted. Soil moisture gained from thermal infrared remote sensing inversion on April 20, 2015 is applied. The transformation result is shown in the following figure.

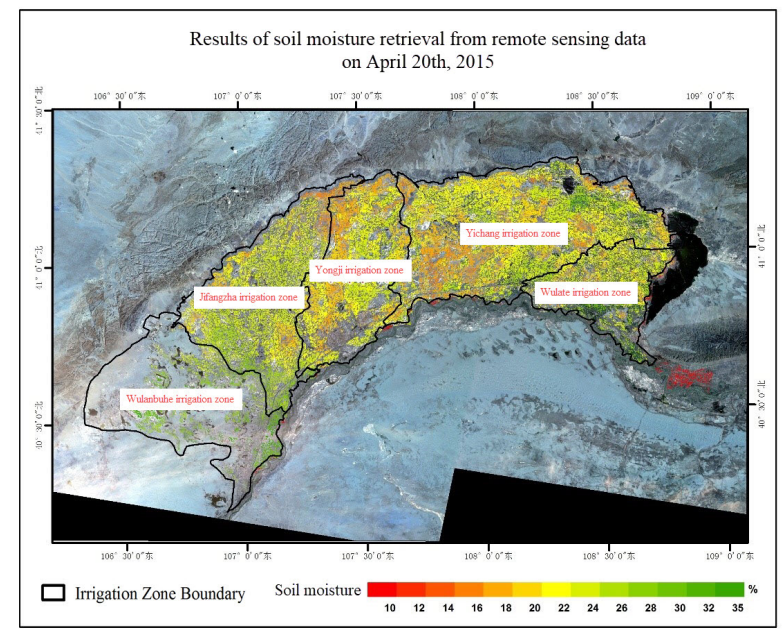

Figure 7. Remote sensing retrieval results of soil moisture in Hetao Irrigation Area on April 20, 2015 


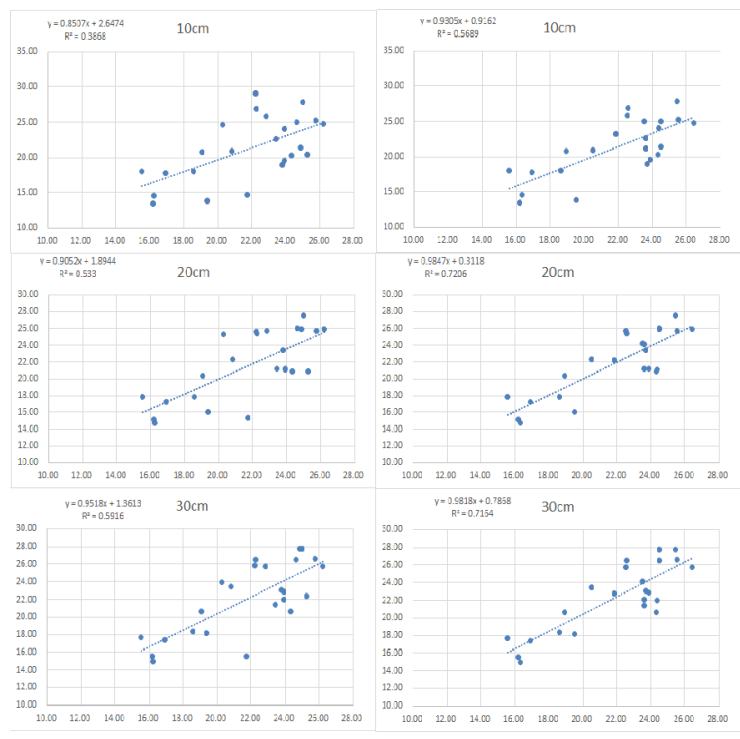

Figure 8. Correlation comparison chart between remote sensing inversion result of soil moisture and ground measured values based on pixel scale and land parcel unit scale on April 20, 2015

Note: Soil layer of depth $10 \mathrm{~cm}, 20 \mathrm{~cm}$ and $30 \mathrm{~cm}$, left figure shows correlation between pixel value and ground measured value; right figure shows correlation between land parcel unit and ground measured value.

The result comparison tables of land where ground measured points of $10 \mathrm{~cm}$ soil layer are and the land for thermal infrared remote sensing of soil moisture after scale transformation are as follows:

\begin{tabular}{|c|c|c|c|c|c|}
\hline $\begin{array}{c}\text { Ground } \\
\text { monitoring } \\
\text { station } \\
\text { number }\end{array}$ & $\begin{array}{l}\text { Soil moisture } \\
\text { of } 10 \mathrm{~cm} \text {-layer } \\
\text { on point scale } \\
\text { measured by } \\
\text { ground } \\
\text { monitoring } \\
\text { station } \%\end{array}$ & $\begin{array}{c}\begin{array}{c}\text { Remote } \\
\text { sensing } \\
\text { retrieval soil } \\
\text { moisture of }\end{array} \\
10 \mathrm{~cm} \text {-layer } \\
\text { on land parcel } \\
\text { unit scale } \%\end{array}$ & $\begin{array}{c}\text { Remote } \\
\text { sensing } \\
\text { retrieval soil } \\
\text { moisture of } \\
10 \mathrm{~cm} \text {-layer } \\
\text { on pixel scale } \\
\%\end{array}$ & $\begin{array}{c}\text { Absolute } \\
\text { difference } \\
\text { between soil } \\
\text { moisture on } \\
\text { point scale } \\
\text { and land } \\
\text { parcel unit } \\
\text { scale } \% \%\end{array}$ & $\begin{array}{c}\text { Absolute } \\
\text { difference } \\
\text { between soi } \\
\text { moisture on } \\
\text { point scale } \\
\text { and pixel } \\
\text { scale } \% \%\end{array}$ \\
\hline $\mathrm{J} 3$ & 21.18 & 23.62 & 26.41 & 2.44 & 5.23 \\
\hline $\mathrm{J} 4$ & 16.04 & 19.5 & 21.19 & 3.46 & 5.15 \\
\hline J5 & 21.09 & 24.37 & 25.91 & 3.29 & 4.82 \\
\hline J6 & 23.45 & 23.7 & 25.78 & 0.26 & 2.33 \\
\hline J7 & 22.33 & 20.52 & 22 & 1.82 & 0.33 \\
\hline J11 & 24.08 & 23.58 & 25.2 & 0.5 & 1.12 \\
\hline J12 & 24.25 & 23.51 & 27.21 & 0.74 & 2.96 \\
\hline J15 & 25.7 & 25.53 & 27.75 & 0.17 & 2.05 \\
\hline W2 & 25.94 & 24.48 & 26.88 & 1.46 & 0.94 \\
\hline Y2 & 15.17 & 16.2 & 18.18 & 1.04 & 3.01 \\
\hline Y3 & 25.97 & 26.42 & 28.22 & 0.45 & 2.25 \\
\hline Y4 & 14.68 & 16.32 & 18.24 & 1.64 & 3.56 \\
\hline Y5 & 25.73 & 22.52 & 23.82 & 3.21 & 1.91 \\
\hline Y6 & 27.53 & 25.45 & 27.01 & 2.08 & 0.52 \\
\hline Y7 & 17.87 & 18.62 & 21.57 & 0.75 & 3.7 \\
\hline Y8 & 20.89 & 24.32 & 26.34 & 3.43 & 5.45 \\
\hline Y9 & 25.48 & 22.59 & 24.25 & 2.89 & 1.23 \\
\hline Y10 & 17.26 & 16.9 & 19.93 & 0.36 & 2.67 \\
\hline Y11 & 17.86 & 15.56 & 17.54 & 2.3 & 0.32 \\
\hline Y12 & 20.33 & 18.94 & 19.05 & 1.4 & 1.28 \\
\hline
\end{tabular}

Table 2. Result comparison table of soil moisture of $10 \mathrm{~cm}-$ layer on point scale measured by ground monitoring station, soil moisture on land parcel unit scale and on pixel scale retrieved by remote sensing

To verify the consistency between measured data of land parcel unit scale and remote sensing, and rationality of land scale remote sensing data, absolute difference of soil moisture of both may be calculated. The result shows that the average error is about $2.10 \%$, and the error is small. It thus can be seen that, land scale transformation method is reliable for scale transformation of remote sensing data. Precision evaluation is conducted through comparing measured soil moisture and remote sensing inversion result of land parcel unit scale. The result shows that it is higher than the remote sensing inversion precision based on pixel.

\section{PROBLEMS AND PROSPECT}

In this research, soil and crop types which greatly influence soil moisture are used to divide the land parcel unit, and geostatistical scale transformation method is utilized to transform soil moisture data of multiple space scales on land parcel unit scale. The transformation result also shows the good correlation with the measured result. Through comparison, it is found that the correlation between soil moisture inversion based on land parcel unit and ground observed value is better than that based on pixel. Land as the research unit can describe spatial distribution characteristics of soil moisture. Meanwhile, relative to high-resolution pixel calculation, it can enhance calculation efficiency. After irrigation progress is added in the simulation, irrigation can be fed back to practical water unit in time, which certainly supports agricultural water management.

At present, there are still some problems in the research which will be further solved and improved. For example, geostatistical method is limited for scale transformation ability, and new scale transformation method based on physical relation between land and pixel needs to be explored. Land parcel unit division principle needs to be further discussed. In this research, several characteristics of underlying surface are used as the division principle. Practical underlying surface is complex. It is necessary to bring more attribute parameters of underlying surface about soil moisture in land division principle.

\section{ACKNOWLEDGEMENTS}

This study was supported by China Institute of Water Resources and Hydropower Research and its being under-taken subject the 13th five-year plan of National Scientific Research and Development: National water resources stereo monitoring system and application of remote sensing technology.[Grant No. 2017YFC0405800].

\section{REFERENCES}

Wang L, Hu Y, Zhao Y and Liu Z, 2012. Remote Sensing Scale Transformation of Soil Moisture Based on Block Kriging. Journal of Geo-Information Science, 14(4), pp. 465-473.

Chi W, 2013. Water Use Performance of Irrigation Area Based on Distributed Hydrological Model. Master Thesis, China Institute of Water Resources and Hydropower Research, Beijing, China.

Zheng J, Li G, Han Z, Meng G, 2011. Application of Modified SWAT Model in Plain Irrigation District. Shui Li Xue Bao, 42(1), pp. 88-97.

Liu X, 2007. The Study on Spatial and Temporal Heterogeneity of Soil Moisture under Different Land in the 
Region of West Shanxi. Master Thesis, Beijing Forestry University, Beijing, China.

Liu Z, 2014. A Study of the Complex and Nonlinear Investigation of Climatological-hydrological Process in the Tarim River Basin. Doctor Thesis, East China Normal University, Shanghai, China.

Revised April 2018 